\title{
Cocaine and Amphetamine Depress Striatal GABAergic Synaptic Transmission through D2 Dopamine Receptors
}

Diego Centonze, M.D., Barbara Picconi, Ph.D., Christelle Baunez, Ph.D., Emiliana Borrelli, Ph.D., Antonio Pisani, M.D., Giorgio Bernardi, M.D., and Paolo Calabresi, M.D.

The striatum is a brain area implicated in the pharmacological action of drugs of abuse. To test the possible involvement of both cocaine and amphetamine in the modulation of synaptic transmission in this nucleus, we coupled whole-cell patch clamp recordings from striatal spiny neurons to the focal stimulation of glutamatergic or GABAergic nerve terminals. We found that neither cocaine (1-600 $\mu \mathrm{M})$ nor amphetamine $(0.3-300 \mu \mathrm{M})$ significantly affected the glutamate-mediated EPSCs recorded from these cells. Conversely, both pharmacological agents depressed GABA-mediated IPSCs in a dose-dependent manner. This effect was mediated by the stimulation of dopamine (DA) $D 2$ receptors since it was prevented by $3 \mu M L$-sulpiride ( $a$ $D A D 2$-like receptor antagonist), mimicked by the DA
D2-like receptor agonist quinpirole $(0.3-30 \mu \mathrm{M})$, and absent in mice lacking DA D2 receptors. A presynaptic mechanism was likely involved in this action since both cocaine and amphetamine depress GABAergic transmission by increasing paired-pulse facilitation. Cocaine and amphetamine failed to affect GABAergic IPSCs after 6-OHDA-induced nigral lesion, indicating that both drugs cause their effects through the release of endogenous DA.

The modulation of GABAergic synaptic transmission in the striatum might underlie some motor and cognitive effects of psychostimulants in mammalians.

Neuropsychopharmacology 26:164-175, 2002]

(C) 2002 American College of Neuropsychopharmacology.

Published by Elsevier Science Inc. All rights reserved.
KEY WORDS: Addiction; Basal ganglia; Electrophysiology; 6-OHDA; Medium spiny neurons; Psychostimulants; Transgenic mice

From the Dipartimento di Neuroscienze, Clinica Neurologica, Università "Tor Vergata" and Fondazione Santa Lucia, IRCCS, Rome, Italy (DC, BP, AP, GB, PC); the Laboratoire de Neurobiologie Cellulaire et Fonctionnelle, LNCF-CNRS UPR9013 Marseille, France (CB); and the Institut de Génétique et de Biologie Moléculaire et Cellulaire, CNRS-INSERM-ULP, CU de Strasbourg, France (EB).

Address correspondence to: Professor Paolo Calabresi, Clinica Neurologica, Dipartimento di Neuroscienze, Università di Tor Vergata, Via di Tor Vergata 135, Rome 00133, Italy; Tel.: +39-06-72596010; Fax: +39-06-7259-6006; e-mail: calabre@uniroma2.it

Received January 25, 2001; revised May 10, 2001; accepted May 25, 2001.

Online publication: 5/31/01 at www.acnp.org/citations/ Npp053101126.
Following psychostimulant administration, markers of brain activity are altered in many areas (Stein and Fuller 1993; Lyons et al. 1996; Breiter et al. 1997), suggesting that the diverse cognitive, emotional, and motor effects of these drugs are caused by the interaction with multiple neuronal systems in the central nervous system. Increasing evidence indicates that not only cortical but also subcortical areas play a role in the cocaine- and amphetamine-mediated effects. In particular, the increased locomotor activity and stereotypy caused by psychostimulants seem to involve specifically the nucleus striatum (Kelly et al. 1975; Amalric and Koob 1993; Berke and Hyman 2000), a structure that receives virtually all the cortical information directed to the basal ganglia (Penney and Young 1983; Albin et al. 1989; McGeorge and Faull 1989; Calabresi et al. 1996; 
Kincaid and Wilson 1996; Parthasarathy and Graybiel 1997; Kaneko et al. 2000). The nucleus striatum also receives profuse dopaminergic innervation from the substantia nigra and has a very high density of D1 and D2 dopamine (DA) receptors but also of D3, D4 and D5 receptors (Mansour and Watson 1995; Surmeier et al. 1996; Bordet et al. 1997; LaHoste et al. 2000).

Amphetamine and cocaine cause in the striatum rapid induction of c-fos, a commonly used molecular marker for neuronal activity. Interestingly, this effect is sensitive to dopamine (DA) receptor blockade (Graybiel et al. 1990; Moratalla et al. 1993), suggesting that increased release of DA in the striatum is responsible, at least in part, for the action of these drugs. In this regard, while the full diversity of drug effects is mediated by multiple neurotransmitters acting in multiple brain regions, most drugs abused by humans share the common property of increasing DA release in this brain area (Di Chiara and Imperato 1988; Kuczenshi et al. 1991; Yamamoto and Spanos 1988; Koob et al. 1998; Ito et al. 2000). Cocaine increases DA availability in the striatum through the blockade of transporter-mediated reuptake of this transmitter, whereas amphetamine exerts its action by promoting DA efflux from DA-containing synaptic endings by reversing the DA uptake transporter (Seiden 1993). Other mechanisms, however, might be involved in the pharmacological actions of cocaine and amphetamine in the striatum. Both drugs, in fact, facilitate serotonin and norepinephrine release (Barker and Blakely 1995; Johanson and Schuster 1995) and cocaine has been found to modulate striatal neuron firing activity in vivo independently of transmitter release but through a direct interaction with sodium channels (Kiyatkin and Rebec 2000).

In the present in vitro study, therefore, we investigated the cellular and synaptic mechanisms implicated in the pharmacological actions of both cocaine and amphetamine on striatal neurons, addressing in detail the dependency of their effects upon the integrity of the DAergic system in this brain area. To achieve these goals we coupled whole-cell patch clamp recordings from striatal projection neurons to the focal stimulation of either corticostriatal glutamatergic or intrinsic GABAergic nerve terminals. We found that both cocaine and amphetamine selectively modulate GABAergic inputs to striatal neurons. This effect was dependent on the release of DA from nigrostriatal nerve terminals since it was absent in corticostriatal slices prepared from rats given severe lesion of the substantia nigra. Finally, we unequivocally identified the DA receptor subtype implicated in the cocaine-, amphetamine-, and DA-mediated depression of striatal GABAergic synaptic transmission by comparing the effects of these pharmacological agents in normal mice with those obtained in transgenic mice selectively lacking D2 DA receptors.

\section{METHODS}

Corticostriatal slices $200-270 \mu \mathrm{m}$ thick were prepared from adult Wistar rats and mice. The preparation and maintenance of coronal slices have been described previously (Calabresi et al. 1997; Centonze et al. 1999). Briefly, coronal slices were prepared from tissue blocks of the brain with the use of a vibratome. A single slice was placed onto the glass coverslip that formed the base of the recording chamber and continuously superfused with Krebs solution $\left(30^{\circ} \mathrm{C}, 2-3 \mathrm{ml} / \mathrm{min}\right)$ gassed with $95 \%$ $\mathrm{O}_{2}+5 \% \mathrm{CO}_{2}$. The composition of the control solution was (in mM): $126 \mathrm{NaCl}, 2.5 \mathrm{KCl}, 1.2 \mathrm{MgCl}_{2}, 1.2 \mathrm{NaH}_{2} \mathrm{PO}_{4}$, $2.4 \mathrm{CaCl}_{2}, 11$ glucose, $25 \mathrm{NaHCO}_{3}$.

Individual striatal neurons were visualized in situ using an Olympus BX50WI (Tokyo, Japan) non-inverted microscope with $40 \times$ water immersion objective combined with an infra-red filter, a monochrome CCD camera (Cohu 4912), and a PC compatible system for analysis of images and contrast enhancement (WinVision 2000, Delta Sistemi, Italy).

Recordings were made with borosilicate glass pi-

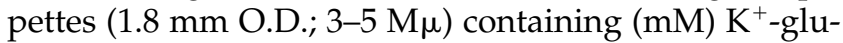
conate (125), $\mathrm{NaCl}$ (10), $\mathrm{CaCl}_{2},(1.0), \mathrm{MgCl}_{2}$ (2.0), 1,2bis (2-aminophenoxy) ethane-N,N,N,N-tetraacetic acid (BAPTA; 1), N-(2-hydroxyethyl)-piperazine-N-2-ethanesulfonic acid (HEPES; 19), guanosine triphosphate (0.3), Mg-adenosine triphosphate (2.0), adjusted to $\mathrm{pH} 7.3$ with $\mathrm{KOH}$. Recording pipettes were advanced towards individual cells in the slice under positive pressure and, on contact, tight $G$ seals were made by applying negative pressure. The membrane patch was then ruptured by suction and membrane current and potential monitored using an Axopatch 1D patch clamp amplifier (Axon Instruments, Foster City, CA). Whole-cell access resistances measured in voltage clamp were in the range of 5-30 M $\mu$ prior to electronic compensation (60-80\% was routinely used).

Voltage steps were generated using pCLAMP software (version 8.0; Axon Instruments, Foster City, CA). For synaptic stimulation, bipolar electrodes were used.

Values given in the text and in the figures are mean \pm SEM of changes in the respective cell populations. Wilcoxon's test or Student's $t$-test (for paired and unpaired observations) were used to compare the means and ANOVA was used when multiple comparisons were made against a single control group. For dose-response curves, the sigmoidal equation best fitting the experimental data was calculated by using the commercially available software Graph Pad Prism (version 2.01), which yielded values for $\mathrm{IC}_{50} \pm \mathrm{SEM}$.

Drugs were applied by dissolving them to the desired final concentration in the saline and by switching the perfusion from control saline to drug-containing saline. Amphetamine and cocaine were generous gifts from Dr. N. B. Mercuri. 6-cyano-7-nitroquinoxaline- 
2,3-dione (CNQX), D-2-amino-5-phosphonovalerate (APV), and (+)-MK 801 maleate (MK-801) were from Tocris (U.K.). Bicuculline (BMI), quinpirole, SCH 23390, and SKF38393 were from RBI (USA). L-sulpiride was from Sigma (Italy).

To obtain unilateral nigrostriatal lesions, rats (anaesthetized with $45 \mathrm{mg} / \mathrm{kg}$ body weight pentobarbitone i.p.) were injected with 6-OHDA ( $8 \mu \mathrm{g} / 4 \mu \mathrm{L}$ of saline containing $0.1 \%$ ascorbic acid) via a Hamilton syringe through a cannula inserted just rostral to the substantia nigra using stereotaxic coordinates (Paxinos and Watson 1986). Twenty days later, the rats were tested with $0.5 \mathrm{mg} / \mathrm{kg}$ s.c. of apomorphine and contralateral turns were counted for $1 \mathrm{hr}$. Only those rats that consistently made at least 400 contralateral turns were used for the electrophysiological studies. In some cases, 6-OHDAlesioned rats were anaesthetized with diethyl ether and brain dissection confirmed that the nigrostriatal pathway was lesioned. This was monitored by using a monoclonal antibody for tyrosine-hydroxylase.

The generation of mice lacking D2 receptors has been reported previously (Baik et al. 1995). The intrinsic and synaptic membrane properties of neurons recorded in vitro from D2 lacking striatal slices were similar to those recorded from wild-type mice and control rats, as previously reported (Calabresi et al. 1997).

\section{RESULTS}

\section{Intrinsic and Synaptic Properties of Striatal Neurons}

Rat striatal medium spiny neurons were identified in corticostriatal slices by morphological and electrophysiological criteria. Striatal spiny neurons had significantly smaller somata than interneurons $(15-25 \mu \mathrm{m}$ vs. $30-60$ $\mu \mathrm{m})$ and displayed high resting membrane potential $(-82 \pm 3 \mathrm{mV})$, action potential discharge with little adaptation during depolarizing current pulses and, when recorded in voltage-clamp mode, a typical current-voltage relationship (Figure 1A). These electrophysiological properties were similar to those reported previously by our group and by others for medium spiny neurons of the striatum (Kita et al. 1984; Jiang and North 1991; Wilson and Kawaguchi 1996; Calabresi et al. 1998).

Both glutamate-mediated post-synaptic inward currents (EPSCs) and GABA-mediated post-synaptic outward currents (IPSCs) were inducible in striatal spiny neurons. To evoke corticostriatal EPSCs, the stimulating electrode was placed close to the recording electrode in the white matter between the cortex and the striatum, whereas it was placed within the striatum to obtain IPSCs. In the presence of the GABAA receptor antagonist BMI $(3 \mu \mathrm{M})$, a single activation of corticostriatal fibres produced EPSCs. At the holding potential $(\mathrm{HP})$ of $-80 \mathrm{mV}$, these synaptic currents (amplitude $330 \pm$

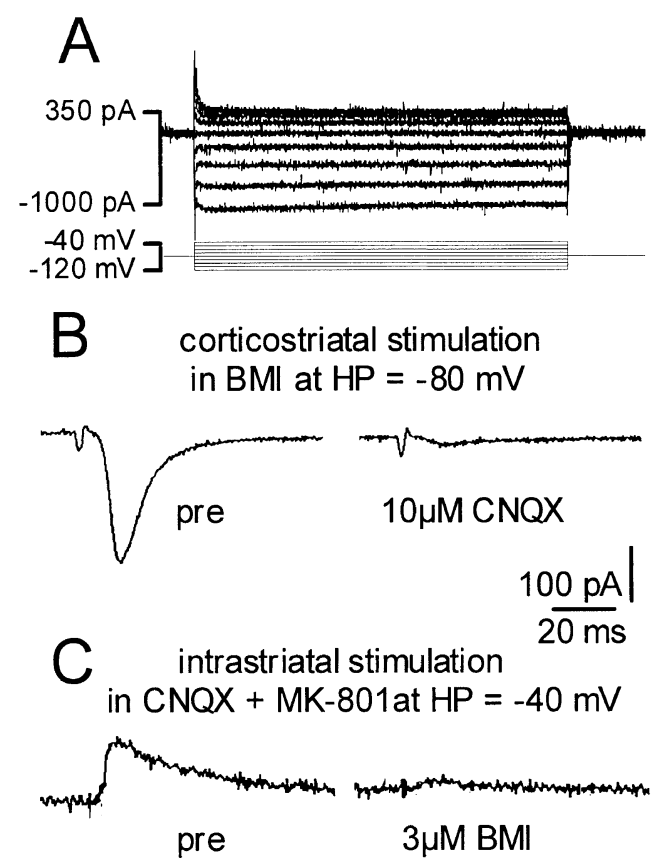

Figure 1. Intrinsic and synaptic properties of striatal neurons. (A) The electrophysiological traces show a typical current-voltage relationship recorded from a striatal spiny neuron in vitro. Plots were obtained from voltage-clamp experiments, holding the cell at $-80 \mathrm{mV}$ and applying positive and negative voltage steps. (B) The electrophysiological traces are corticostriatal EPSCs recorded in the presence of the GABAA receptor antagonist BMI at $\mathrm{HP}$ of $-80 \mathrm{mV}$ before (left) and $5 \mathrm{~min}$ after the application of the glutamate AMPA receptor antagonist CNQX (right). (C) The electrophysiological traces are striatal IPSCs recorded from another striatal neuron in the presence of the glutamate receptor antagonists MK-801 and CNQX at $\mathrm{HP}$ of -40 $\mathrm{mV}$ before (left) and $5 \mathrm{~min}$ after the application of BMI (right).

$148 \mathrm{pA}$ ) were not affected by the NMDA glutamate receptor antagonists MK-801 $(30 \mu \mathrm{M}, \mathrm{n}=6)$ or APV (50 $\mu \mathrm{M}, \mathrm{n}=5$ ), while they were fully abolished by $10 \mu \mathrm{M}$ CNQX, an AMPA glutamate receptor antagonist $(\mathrm{n}=8)$ (Figure 1B). GABA-mediated synaptic currents (amplitude $160 \pm 50 \mathrm{pA}$ ) were conversely recorded following intrastriatal stimulation in the presence of MK-801 (30 $\mu \mathrm{M})$ or APV $(50 \mu \mathrm{M})$ and CNQX $(10 \mu \mathrm{M})$. These currents were completely sensitive to BMI $(3 \mu \mathrm{M} ; \mathrm{n}=25)$ and were detected as outward deflections when the membrane potential of the cells was depolarized to -40 $\mathrm{mV}$ (Figure 1C). At HP of $-80 \mathrm{mV}$, conversely, the bicuculline-sensitive GABAA-mediated synaptic currents were usually detected as inward events of small amplitude $(\sim 20-50 \quad \mathrm{pA})$. In this study, therefore, all glutamate-mediated EPSCs and GABAA-dependent IPSCs were recorded at HPs of $-80 \mathrm{mV}$ and $-40 \mathrm{mV}$, respectively. In these experimental conditions, the amplitude of both inward and outward currents recorded from striatal spiny neurons depended on the intensity 


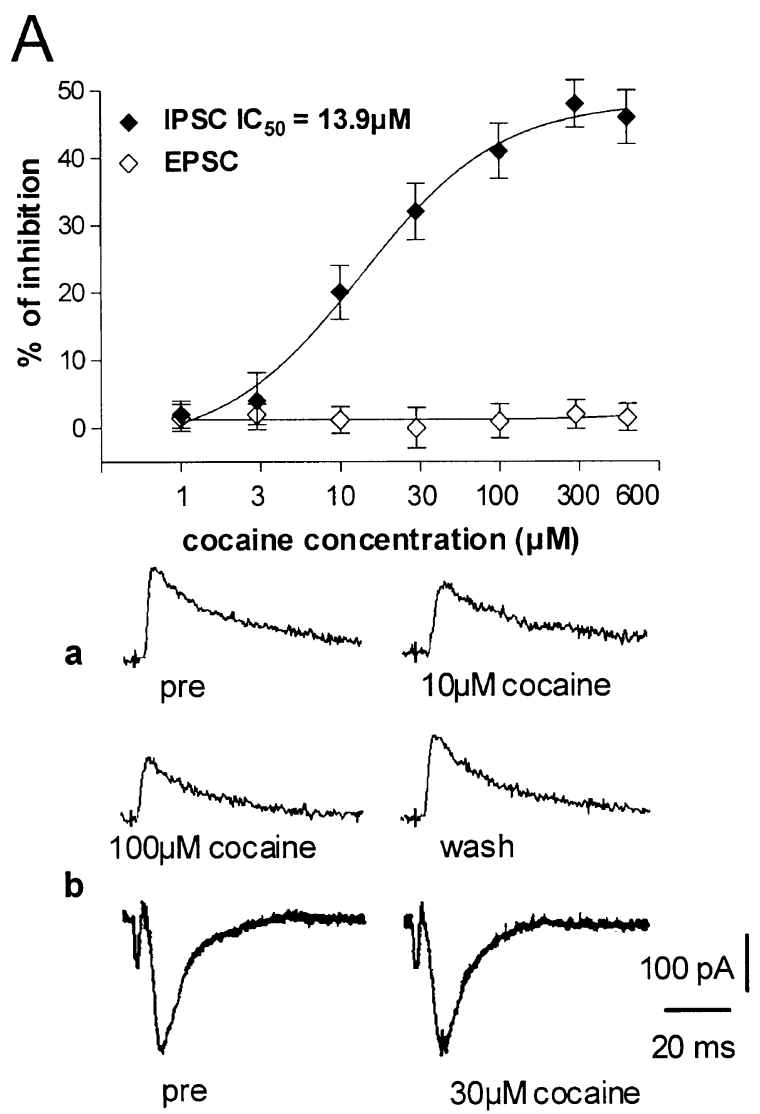

B

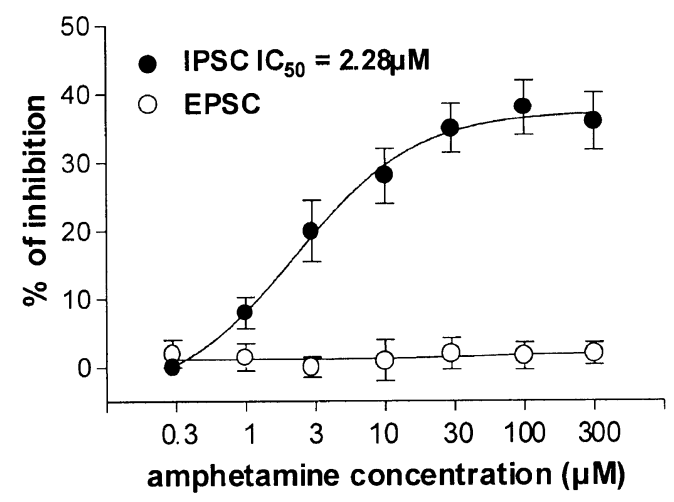

a
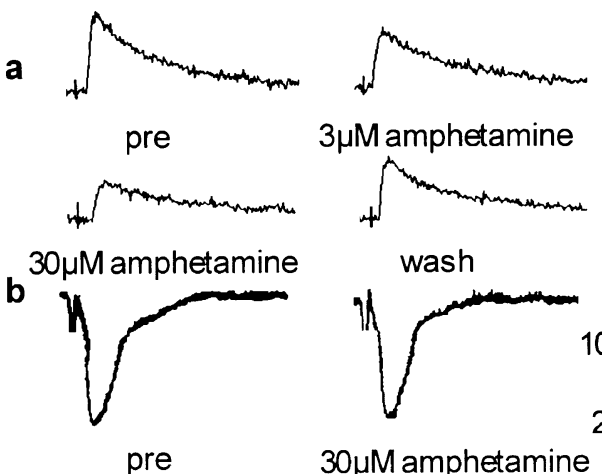

$3 \mu \mathrm{M}$ amphetamine

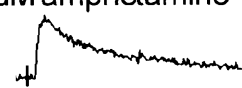

wash

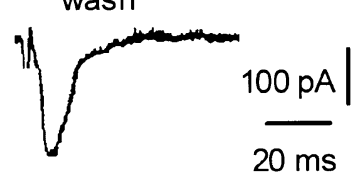

30 $\mu \mathrm{M}$ amphetamine

Figure 2. The inhibitory effects of both cocaine and amphetamine on striatal GABAergic IPSCs are dose-dependent. (A) Dose-response relationships of the effects of cocaine of stimulation and the distance between the stimulating and the recording sites.

\section{Effects of Cocaine and Amphetamine on Striatal Synaptic Transmission and Cell Membrane Properties}

We investigated the possible modulatory action of psychostimulants on both excitatory and inhibitory synaptic transmission on the striatum. Cocaine $(30-600 \mu \mathrm{M}, 10 \mathrm{~min}$ bath application, $n=8)$ and amphetamine $(30-300 \mu \mathrm{M}$, 10 min bath application, $n=9)$ produced no detectable effects on the amplitude of corticostriatal EPSCs $(p>.05$ for each compound at each concentration), while both drugs were found capable of causing a marked depression of IPSC amplitude $(n=24$ for cocaine and $n=26$ for amphetamine). The cocaine and amphetamine inhibition of GABAergic IPSCs was concentration dependent with minimal effects produced by $10 \mu \mathrm{M}$ cocaine $(p<.01)$ or $1 \mu \mathrm{M}$ amphetamine $(p<.05)$ and maximal inhibition caused by $100-600 \mu \mathrm{M}$ cocaine $(p<.001$ for each concentration) or 30-300 $\mu \mathrm{M}$ amphetamine $(p<$ .001 for each concentration). The calculated $\mathrm{IC}_{50}$ was $13.9 \pm 1.4 \mu \mathrm{M}$ for cocaine and $2.28 \pm 1.2 \mu \mathrm{M}$ for amphetamine (Figure 2). This effect was fully reversible after 15-20 min wash and was not associated with changes either in the reversal potential of the GABA-mediated synaptic currents nor in the holding current and membrane conductance of the recorded striatal neurons $(p>$ .05 for each electrophysiological parameter) (Figure 3). This latter electrophysiological parameter was calculated by measuring the current drops produced from the HP of $-40 \mathrm{mV}$ or $-80 \mathrm{mV}$ by $5 \mathrm{mV}$ voltage steps in hyperpolarizing direction.

\section{Effects of DA Denervation and of Pharmacological Blockade of DA D1- and D2-like Receptors on the Cocaine- and Amphetamine-induced Inhibition of Striatal GABAergic Transmission}

Although it is generally believed that psychostimulants exert their physiological actions by increasing the levels of endogenous DA in critical brain areas, it has been re-

on striatal IPSCs and EPSCs. The electrophysiological traces represent IPSCs (a) and EPSCs (b) recorded from two different striatal neurons in control medium (pre), in the presence of $10 \mu \mathrm{M}$ cocaine, in the presence of $100 \mu \mathrm{M}$ cocaine, and $15 \mathrm{~min}$ after the wash of the drug. (B) Dose-response relationships of the effects of amphetamine on striatal IPSCs and EPSCs. The electrophysiological traces represent IPSCs and EPSCs recorded from two other striatal neurons in control medium, in the presence of $3 \mu \mathrm{M}$ amphetamine, in the presence of $30 \mu \mathrm{M}$ amphetamine, and $15 \mathrm{~min}$ after the wash out of the drug. 

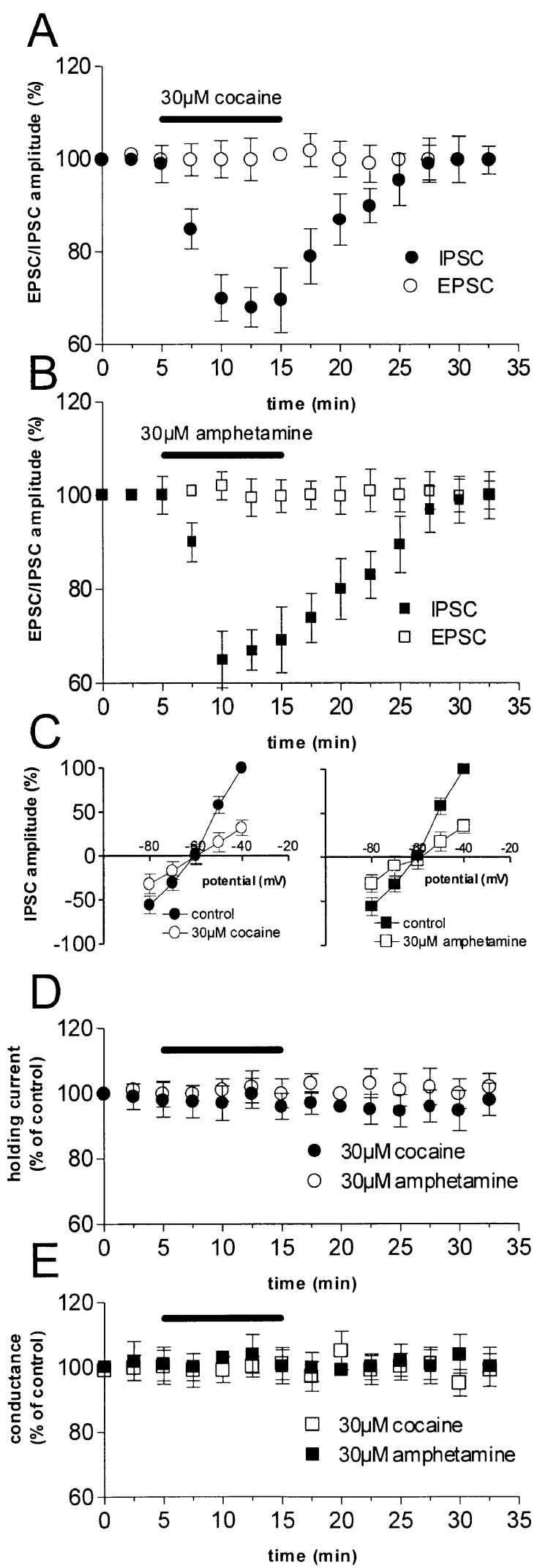

Figure 3. Psychostimulants depress striatal IPSCs. (A) The graph shows that bath application of cocaine causes a marked and reversible inhibition of striatal GABAergic transmission. Corticostriatal EPSCs are conversely unaf- cently reported that cocaine modulates striatal neuron firing activity independently of a DA-mediated mechanism (Kiyatkin and Rebec 2000). To test whether the inhibitory effect of both cocaine and amphetamine on striatal GABAergic transmission was caused by the action of these drugs on DAergic nerve terminals of the striatum, we recorded striatal neurons from rats with 6-OHDA-induced lesion of the homolateral substantia nigra. This brain area represents the main source of DAergic terminals in the striatum and the nigral injection of 6-OHDA causes virtually complete disappearance of DA-containing striatal fibers (Calabresi et al. 1993).

As shown in Figure $4 \mathrm{~A}$, cocaine $(30 \mu \mathrm{M})$ failed to produce a significant inhibition of IPSCs in DA-denervated striatal slices $(n=7 ; p>.05)$, indicating that the integrity of DA innervation is a crucial requirement for the modulatory action of cocaine on GABAergic transmission in the striatum. Moreover, the electrophysiological effects of cocaine on striatal IPSCs were also fully prevented by the DA D2-like receptor antagonist L-sulpiride ( $3 \mu \mathrm{M}, 15$ min bath application) $(n=6 ; p>$ .05) but not by $10 \mu \mathrm{M}$ SCH 23390 (15 min; $n=6$; $p<$ .01 ), a DA D1-like receptor antagonist (Figure 4A). Essentially similar results were obtained with $30 \mu \mathrm{M}$ amphetamine (6-OHDA lesion: $n=6, p>.05$; 7-15 min L-sulpiride $3 \mu \mathrm{M}: n=7, p>.05 ; 15 \min$ SCH 2339010 $\mu \mathrm{M}: n=4, p<.01$ ) (Figure 4C).

Since either a decreased release of neurotransmitter or a decreased postsynaptic sensitivity to GABA can be responsible for the cocaine- and amphetamine-induced inhibition of striatal IPSCs, we tried to distinguish these possibilities through paired pulse experiments performed with interstimulus interval of 40-80 ms. No change in IPSC2/IPSC1 ratio (normally positive to 1 ) would accompany the depression of IPSCs if this synaptic inhibition is caused by a reduced postsynaptic sensitivity to GABA. As shown in Figures 4B and 4D, however, both cocaine and amphetamine depressed striatal GABAergic transmission by increasing IPSC2/ IPSC 1 ratio $(n=8$ and $p<.01$ for each experimental condition), strongly implying in this pharmacological effect a presynaptic site of action. Together, these data demonstrate that both cocaine and amphetamine increase intrastriatal levels of endogenous DA, which, in

fected by this pharmacological agent. (B) Similarly, the application of amphetamine depresses striatal GABAergic transmission without affecting corticostriatal glutamatemediated synaptic currents. (C) Both cocaine (left) and amphetamine (right) depress GABA-mediated IPSCs without altering the reversal potential of these currents recorded in control medium. (D, E) The graphs show that both cocaine and amphetamine affected neither the holding current (D) nor the membrane conductance (E) of the recorded striatal neurons. 


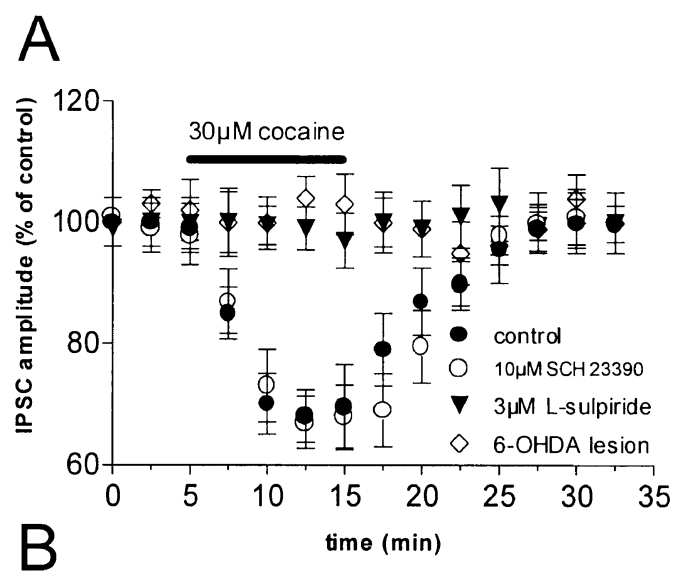

turn, depresses GABAergic synaptic transmission by activating at least one subtype of presynaptic DA receptors composing the D2-like family (D2, D3, D4, and their variants).

\section{Effects of DA Agonists on Striatal GABAergic Transmission and on Cocaine- and Amphetamine-induced Depression of IPSCs}

To further strengthen the idea that psychostimulants exert their effect on striatal GABAergic transmission through a DA-dependent mechanism, we tried to mimic the electrophysiological actions of cocaine and amphetamine by using selective agonists of DA D1and D2-like receptors. Bath application (7-10 $\mathrm{min})$ of the DA D2-like receptor agonist quinpirole $(n=12 ; p<$ .01 at 3,10 and $30 \mu \mathrm{M}$ ) but not of the DA D1-like receptor agonist SKF $38393(n=5 ; p>.05$ at each concentration) produced a dose-dependent inhibition of striatal IPSCs $\left(\mathrm{IC}_{50}=3.38 \pm 0.8 \mu \mathrm{M}\right)$ (Figure 5A). This effect was not associated with changes in the intrinsic membrane properties of the recorded cells and was only partially reversible at the wash-out of the drug. In most cases, in fact, the administration of L-sulpiride $(3 \mu \mathrm{M})$ was required to fully restore the IPSC amplitude obtained in control condition (not shown). As with cocaine and amphetamine and according to a previous report (Delgado et al. 2000), quinpirole-induced reduction of striatal GABAergic IPSCs was coupled to a significant increase in paired pulse facilitation $(n=8 ; p<.01)$ (Figure $5 \mathrm{~B}$ ), indicating that the inhibitory action of this DAergic agonist on GABAergic synaptic currents was mediated by the activation of DA D2-like receptors located on presynaptic nerve terminals. Moreover, quinpirole occluded the cocaine- or amphetamine-induced depression of striatal GABAergic transmission, as demonstrated by the finding that in the presence of $10 \mu \mathrm{M}$ quinpirole no further depression of striatal IPSCs was inducible by cocaine $(30 \mu \mathrm{M})(n=7 ; p>.05)$ or by amphetamine $(30 \mu \mathrm{M})(n=4 ; p>.05)$ (Figure 5C). Similarly, when the application of cocaine $(30 \mu \mathrm{M} ; n=4)$ (Figure 5D) or amphetamine $(30 \mu \mathrm{M} ;(n=5)$ (not shown) preceded the application of quinpirole, this DA

histogram shows that cocaine depresses striatal IPSCs by increasing paired pulse facilitation evoked by a pair of synaptic stimuli delivered $40-80 \mathrm{~ms}$ apart $\left({ }^{* *} p<.01\right)$. (C) The graph shows the effects of amphetamine on striatal IPSCs recorded in control condition (filled squares), in the presence of the D1-like DA receptor antagonist SCH23390 (10 $\mu \mathrm{M}$, open triangles), in the presence of the D2-like DA receptor antagonist L-sulpiride ( $3 \mu \mathrm{M}$, filled triangles), and in 6OHDA-treated rats (open diamonds). (D) The histogram shows that amphetamine depresses striatal IPSCs by increasing paired pulse facilitation $\left.{ }^{* *} p<.01\right)$. 

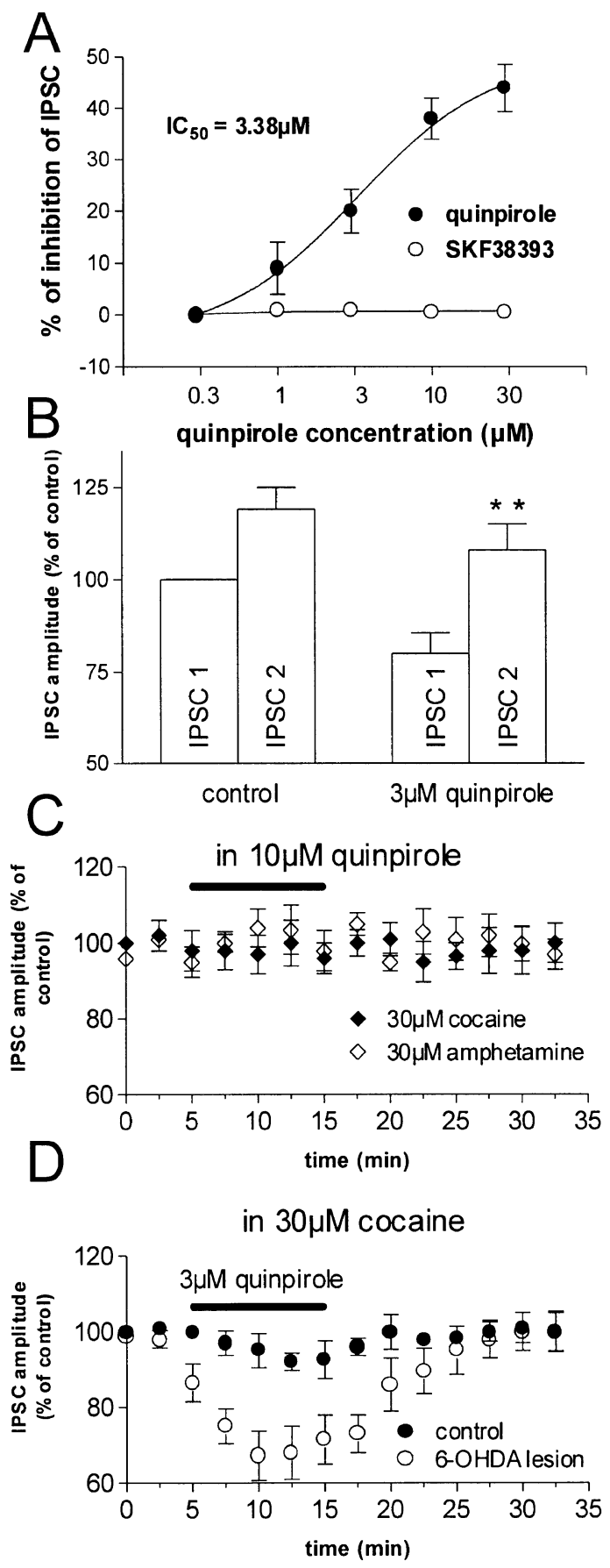

Figure 5. Stimulation of D2-like DA receptors mimics and occludes cocaine- and amphetamine-induced inhibition of striatal IPSCs. (A) Dose-response relationships of the effects of the D2-like DA receptor agonist quinpirole and of the D1like DA receptor agonist SKF38393 on striatal IPSCs. (B) The histogram shows that quinpirole depresses striatal IPSCs by increasing paired pulse facilitation $\left({ }^{* *} p<0.01\right)$. (C) The graph shows the effects of both cocaine (filled diamonds) and amphetamine (open diamonds) on IPSCs evoked from striatal slices bathed in $10 \mu \mathrm{M}$ quinpirole. (D) Quinpirole depresses striatal IPSCs recorded in the presence of $30 \mu \mathrm{M}$ cocaine in 6-OHDA-treated rats (open circles) but not in control animals (filled circles). agonist failed to further depress striatal IPSCs in control slices ( $p>.05$ for each experimental condition). Conversely, quinpirole produced a robust inhibition of the synaptic currents evoked in DA-denervated striatal slices (Figure 5D) $(n=7 ; p<.01)$, which were insensitive to both psychostimulants (see above and Figure 4). These observations indicate that cocaine and amphetamine inhibit GABAergic transmission in the striatum through a mechanism shared by quinpirole, that is, the stimulation of DA D2-like receptors. Moreover, the evidence that quinpirole does inhibit GABAergic transmission in DA-denervated striatal slices demonstrates that in these slices the failure in affecting IPSCs by both cocaine and amphetamine is not caused by the disruption of the D2-like-receptor-dependent regulation of GABA release.

\section{Effects of the Genetic Disruption of DA D2 Receptors on Cocaine-, Amphetamine-, and Quinpirole-induced Depression of Striatal GABAergic Transmission}

Since the available pharmacological tools do not allow discriminating among the various DA receptors included in the D2-like receptor family, we measured the effects of both cocaine and amphetamine on striatal GABAergic IPSCs recorded from transgenic mice selectively lacking D2 receptors. As already reported (Calabresi et al. 1997), the intrinsic and synaptic properties of striatal neurons recorded from these mice were indistinguishable from those of their wild-type counterparts and from rat striatal neurons (not shown). In these mice, however, both cocaine $(30 \mu \mathrm{M})(n=4 ; p>.05)$ and amphetamine $(30 \mu \mathrm{M})(n=4 ; p>.05)$ failed to affect striatal IPSCs (Figures 6A and 6B), implying DA D2 receptors in the pharmacological action of these drugs within the striatum. As expected, neither did $10 \mu \mathrm{M}$ quinpirole produce significant effects on striatal GABAA-mediated transmission in D2 lacking mice $(\mathrm{n}=$ 3; $p>0.05$ ), whereas cocaine, amphetamine and quinpirole normally inhibited striatal IPSCs in control mice (Figure $6 \mathrm{C})(n=4$ and $p<.01$ for each experimental condition).

\section{DISCUSSION}

The present results demonstrate that both cocaine and amphetamine depress striatal GABAergic transmission by favoring DA release from nigrostriatal nerve terminals which, in turn, acts by stimulating D2 DA receptors. Glutamate-mediated corticostriatal synaptic transmission is conversely unaffected by these addictive drugs. The enhancement of paired pulse facilitation, together with the lack of any postsynaptic action of these compounds on IPSC reversal potential, holding current 

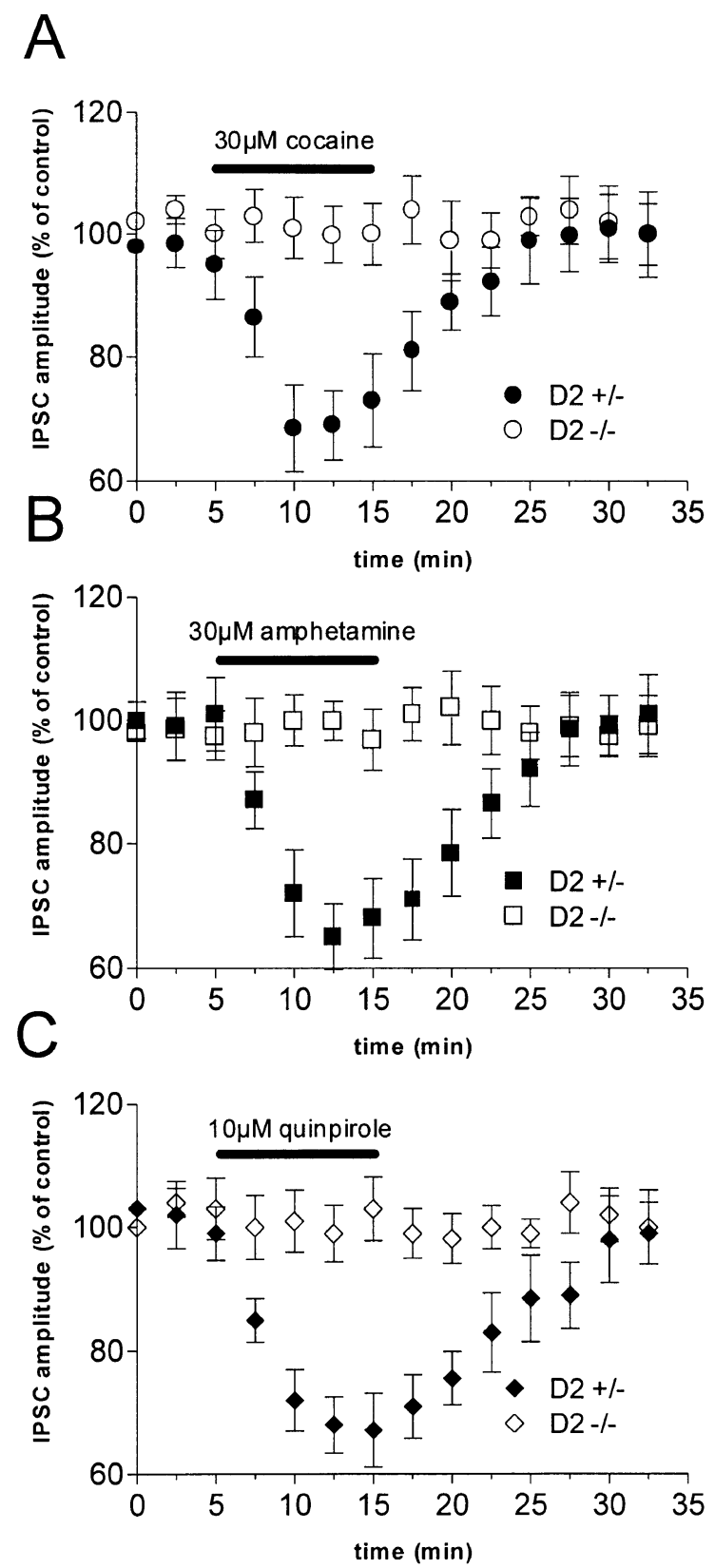

Figure 6. Effects of the genetic disruption of D2 DA receptors on cocaine-, amphetamine-, and quinpirole-induced inhibition of striatal IPSCs. (A) Cocaine depresses striatal IPSCs in wild-type but not in transgenic mice lacking D2 receptors. (B) Amphetamine depresses striatal IPSCs in wild-type but not in transgenic mice lacking D2 receptors. (C) Quinpirole depresses striatal IPSCs in wild-type but not in transgenic mice lacking D2 receptors.

and membrane conductance, all point to a presynaptic site for this action. Accordingly, although DA receptors are abundantly expressed postsynaptically on striatal neurons (Surmeier et al. 1996), their activation is known to modulate membrane conductances operating in voltage ranges far from the values chosen in this study to evoke synaptic events $(-80 \mathrm{mV}$ and $-40 \mathrm{mV})$ (Schiffmann et al. 1995; Surmeier et al. 1995; Lin et al. 1996; Hernandez-Lopez et al. 2000). This observation, therefore, further confirms that the postsynaptic effects of DA receptor activation cannot be responsible for the observed modulation of striatal IPSCs.

In a recent in vivo study, cocaine was found to exert a preferential local-anaesthetic-like action on striatal neurons (Kiyatkin and Rebec 2000), suggesting that this kind of effect might in principle have occurred in our experimental condition. The quiescent behavior of spiny neurons in vitro, however, prevented the observation of cocaine effects on voltage dependent-sodium channels. Accordingly, the effects of cocaine described here were fully blocked by DA antagonists, DA-denervation and D2 receptor genetic disruption, demonstrating that they were not caused by DA-independent actions.

\section{Anatomo-functional Characteristics of Synaptic Inputs to Striatal Neurons}

Glutamate-mediated excitatory synaptic inputs and GABA-dependent inhibitory potentials govern striatal neuron firing activity. GABAergic medium spiny projection neurons, which account for about $95 \%$ of the whole neuronal population of the striatum, in fact, are silent at rest and fire action potentials only when depolarized by glutamate released from corticostriatal and thalamostriatal terminals (Calabresi et al. 1996; Wilson and Kawaguchi 1996; Stern et al. 1998). GABAergic inputs to these neurons, conversely, are essentially intrinsic and tend to counter the excitatory action of glutamate (Kita 1996; Plentz and Kitai 1998). Accordingly, in vivo, blockade of ongoing GABAergic inhibition of medium spiny neurons significantly elevates basal activity (Nisenbaum and Berger 1992), supporting the idea that psychostimulants, by inhibiting GABAergic inhibition, would substantially enhance the ability of cortical activity to evoke spiking in medium spiny neurons. Recurrent collaterals of projection neurons and GABAergic interneurons, such as fast-spiking and parvalbumin-immunoreactive cells contact striatal spiny neurons in their somato-dendritic region (Wilson and Groves 1980; Yung et al. 1996; Bennet and Bolam 1994; Plentz and Kitai 1998; Koos and Tepper 1999) and express D2 DA receptors (Lenz et al. 1994; Delle Donne et al. 1997; Aizman et al. 2000). It is therefore conceivable that terminals from all these different cell types would also possess D2 DA receptor and be sensitive to a similar extent to the pharmacological action of psychostimulants. Recent electrophysiological evidence, however, strengthened the idea that among the various GABAergic inputs to spiny neurons, those originating from fast-spiking interneurons exert the predominant inhibitory control on the functional activity of these cells. Although it has been proposed that recurrent col- 
laterals of spiny neurons provide an important feedback inhibition in the striatum (Wilson and Groves 1980; Beiser and Houk 1998; Wickens et al. 1995), functional studies showed that mutual inhibitory interaction between medium spiny neurons is conversely very weak or non-existent (Jaeger et al. 1994). By contrast, action potentials evoked in a fast-spiking interneuron have been found capable to produce GABA-mediated synaptic events in nearby medium spiny neurons, dramatically impacting spike generation and timing in these cells (Plentz and Kitai 1998; Koos and Tepper 1999). These observations, therefore, suggest that the GABAergic nerve terminals stimulated in our study to produce IPSCs were likely those of striatal fast-spiking interneurons, the transmitter release of which appeared to be modulated by cocaine and amphetamine via DA receptors.

\section{Comparison with Other Electrophysiological Studies}

Cocaine has been shown to cause a strong inhibition of striatal neurons in vivo (Qiao et al. 1990; White et al. 1993; Kiyatkin and Rebec 2000). This inhibitory effect was highly dependent on the activity state of the neuron (being generally undetectable in slow-firing cells and maximal in fast-firing neurons), and was attributed, at least in part, to a DA-independent local-anesthetic-like interaction with sodium transport (Kiyatkin and Rebec 2000). Taken together with our in vitro data, these observations indicate that cocaine, by preventing synaptic inhibition through a DA-dependent mechanism, preferentially enhances the excitability of spiny neurons weakly activated, whereas, through a partially DA-independent action, it preferentially inhibits firing activity when striatal neurons are massively stimulated. This dual action of cocaine might force striatal neurons to fire constantly action potentials within a narrow intermediate interval rate, altering profoundly the physiological activity of these cells, normally oscillating between a very quiescent "down" state and a very active "up" state (Calabresi et al. 1996; Wilson and Kawaguchi 1996; Stern et al. 1998).

A recent in vitro study reported that neither DA nor amphetamine depressed GABAergic synaptic transmission in the dorsal striatum (Nicola and Malenka 1998). Although we have no conclusive explanation for the discrepancy existing between this study and our report, it is possible that different experimental conditions might account for these contrasting results. We can speculate that the two studies differ for the location of the stimulating electrodes producing GABAergic responses. This different arrangement of the electrodes might activate heterogeneous GABAergic terminals showing different sensitivity to D2 DA receptor agonists.

Conflicting results also exist on the possible role of
D2-like receptors in the modulation of excitatory transmission in the dorsal striatum. Some laboratories, in fact, reported that DA D2-like receptor activation depressed excitatory synaptic transmission in this brain area, either presynaptically (Hsu et al. 1995; Cepeda et al. 2001) or postsynaptically (Cepeda et al. 1992; Levine et al. 1996). In contrast, our group and others found that, at least under control conditions, activation of D2like receptors caused significant changes neither of glutamate-mediated synaptic potentials (Calabresi et al. 1988; Calabresi et al. 1992; Calabresi et al. 1993; Nicola and Malenka 1998; Pisani et al. 2000; present study) nor of exogenous applied AMPA and glutamate (Calabresi et al. 1995). A D2-like-receptor-dependent attenuation of excitatory transmission was conversely observed only in slices taken from animals exposed to treatments intended to upregulate D2 receptors, as obtained following chronic administration of reserpine (Calabresi et al. 1988) and haloperidol (Calabresi et al. 1992) and 6-OHDA-induced nigrostriatal denervation (Calabresi et al. 1993). Although reconciling all these experimental data is not simple, the heterogeneous distribution of active D2-like receptors on corticostriatal terminals might partially account for these conflicting results. Accordingly, a recent study reported that the presynaptic D2-likereceptor-dependent inhibition of spontaneous excitatory potentials induced in the striatum by 4 -aminopyridine was observed only in a subset of striatal neurons (Flores-Hernàndez et al. 1997).

\section{Functional Implications}

Current models of the basal ganglia propose that the striatum is an important component of sensorimotor, cognitive, and limbic circuits, as also suggested by the anatomical evidence that this brain area receives inputs not only from the motor cortex but also from sensory, cingulated, and association neocortical areas (Albin et al. 1989; Graybiel et al. 1994). These non-motor connections account, at least in part, for the involvement of the striatum in memory formation, mnemonic guidance of behavior and rewarding processes (Whishaw et al. 1987; Saint-Cyr et al. 1988; Knowlton et al. 1996; Graybiel 1998; Apicella et al. 1991). Interestingly, most recent investigations into the molecular neurobiology of addiction have emphasized the view that addictive drugs lead to the compulsive nature of drug abuse and to the persistent tendency to relapse by engaging a set of molecular mechanisms normally involved in striatally based associative learning and reward. These processes critically depend on the integrity of the DAergic signal in this brain area, since disturbance of striatal DA system severely interferes with these physiological abilities (see Berke and Hyman 2000 for a comprehensive review of these concepts).

We propose, in conclusion, that the DA-dependent 
modulation of striatal inhibitory synaptic transmission by cocaine and amphetamine might play a role in the development of those drug-taking behaviors critical for addiction.

\section{ACKNOWLEDGMENTS}

We thank Mr. Massimo Tolu for technical assistance. This work was supported by the following grants: BIOMED (BMH4-97-2215) and Telethon ( $\mathrm{N}^{\circ}$ E.729) to PC, MURST-CNR (legge 95/95) to GB, and Telethon ( $\mathrm{N}^{\circ}$ E.0930) to AP.

\section{REFERENCES}

Aizman O, Brismar H, Uhlen P, Zettergren E, Levey AI, Forssberg H, Greengard P, Aperia A (2000): Anatomical and physiological evidence for D1 and D2 dopamine receptor colocalization in neostriatal neurons. Nat Neurosci 3:226-230

Albin RL, Young AB, Penney JB (1989): The functional anatomy of basal ganglia disorders. Trends Neurosci 12:366-375

Amalric M, Koob GF (1993): Functionally selective neurochemical afferents and efferents of the mesocorticolimbic and nigrostriatal dopamine system. Prog Brain Res 99:209-226

Apicella P, Ljungberg T, Scarnati E, Schultz W (1991): Responses to reward in monkey dorsal and ventral striatum. Exp Brain Res 85:491-500

Baik JH, Picetti R, Saiardi A, Thiriet G, Dierich A, Depaulis A, Le Meur M, Borrelli E (1995): Parkinsonian-like locomotor impairment in mice like dopamine D2 receptors. Nature 377:424-428

Barker EL, Blakely RD (1995): Norepinephrine and serotonin transporters. Molecular targets of antidepressant drugs. In Bloom FS, Kupfer DJ (eds), Psychopharmacology: The Fourth Generation of Progress. New York, Raven Press, pp 321-333

Beiser DG, Houk JC (1998): Model of cortical-basal ganglionic processing: encoding the serial order of sensory events. J Neurophysiol 79:3168-3188

Bennett BD, Bolam JP (1994): Synaptic input and output of parvalbumin-immunoreactive neurons in the neostriatum of the rat. Neuroscience 62:707-719

Berke JD, Hyman SE (2000): Addiction, dopamine, and the molecular mechanisms of memory. Neuron 25:515-532

Bordet R, Ridray S, Carboni S, Diaz Y, Sokoloff P, Schwartz JC (1997): Induction of dopamine D3 receptor expression as a mechanism of behavioral sensitization to levodopa. Proc Natl Acad Sci USA 94:3363-3367

Breiter HC, Gollub RL, Weisskoff RM, Kennedy DN, Makris N, Berke JD, Goodman JM, Kantor HL, Gastfriend DR, Riorden JP, Mathew RT, Rosen BR, Hyman SE (1997): Acute effects of cocaine on human brain activity and emotion. Neuron 19:591-611

Calabresi P, Benedetti M, Mercuri NB, Bernardi G (1988): Endogenous dopamine and dopaminergic agonists modulate synaptic excitation in neostriatum: intracellular studies from naive and catecholamine-depleted rats. Neuroscience 27:145-157
Calabresi P, Centonze D, Pisani A, Sancesario G, Gubellini P, Marfia GA, Bernardi G (1998): Striatal spiny neurons and cholinergic interneurons express differential ionotropic glutamatergic responses and vulnerability: implications for ischemia and Huntington's disease. Ann Neurol 43:586-597

Calabresi P, De Murtas M, Mercuri NB, Bernardi G (1992): Chronic neuroleptic treatment: D2 dopamine receptor supersensitivy and striatal glutamatergic transmission. Ann Neurol 31:366-373

Calabresi P, De Murtas M, Pisani A, Stefani A, Sancesario G, Mercuri NB, Bernardi G (1995) Vulnerability of medium spiny striatal neurons to glutamate: role of $\mathrm{Na} / \mathrm{K}$ ATPase. Eur J Neurosci 7:1674-1683

Calabresi P, Mercuri NB, Sancesario G, Bernardi G (1993): Electrophysiology of dopamine-denervated striatal neurons: implications for Parkinson's disease. Brain 116:433-452

Calabresi P, Pisani A, Mercuri NB, Bernardi G (1996): The corticostriatal projection: from synaptic plasticity to dysfunctions of the basal ganglia. Trends Neurosci 19:19-24

Calabresi P, Saiardi A, Pisani A, Baik J-H, Centonze D, Mercuri N, Bernardi G, Borrelli E (1997): Abnormal synaptic plasticity in the striatum of mice lacking dopamine D2 receptors. J Neurosci 17:4536-4544

Centonze D, Gubellini P, Picconi B, Calabresi P, Giacomini P, Bernardi G (1999): Unilateral dopamine denervation blocks corticostriatal LTP. J Neurophysiol 82:3575-3579

Cepeda C, Buchwald NA, Levine MS (1992): Neuromodulatory actions of dopamine in the neostriatum are dependent upon the excitatory amino acid receptor subtypes activated. Proc Natl Acad Sci USA 90:9576-9580

Cepeda C, Hurst RS, Altemus KL, Flores-Hernàndez J, Calvert CR, Jokel ES, Grandy DK, Low MJ, Rubinstein M, Ariano MA, Levine MS (2001): Facilitated glutamatergic transmission in the striatum of $\mathrm{D}_{2}$ dopamine receptordeficient mice. J Neurophysiol 85:659-670

Delgado A, Sierra A, Querejeta E, Valdiosera RF, Aceves J (2000): Inhibitory control of the GABAergic transmission by D2 dopamine receptors. Neuroscience 95:10431048

Delle Donne KT, Sesack SR, Pickel VM (1997): Ultrastructural immunocytochemical localization of the dopamine D2 receptor within GABAergic neurons in the rat striatum. Brain Res 746:239-255

Di Chiara G, Imperato A (1988): Drugs abused by humans preferentially increase synaptic dopamine concentrations in the mesolimbic system of freely moving rats. Proc Natl Acad Sci USA 85:5274-5278

Flores-Hernàndez J, Gallaraga E, Bargas J (1997): Dopamine selects glutamatergic inputs to neostriatal neurons. Synapse 25:185-195

Graybiel AM (1998): The basal ganglia and chunking of action repertoires. Neurobiol Learn Mem 70:119-136

Graybiel AM, Aosaki T, Flaherty A, Kimura M (1994): The basal ganglia and adaptive motor control. Science 265:1826-1831

Graybiel AM, Moratalla R, Robertson HA (1990): Amphetamine and cocaine induce drug-specific activation of the c-fos gene in striosome-matrix compartments and 
limbic subdivisions of the striatum. Proc Natl Acad Sci USA 87:6912-6916

Hernandez-Lopez S, Tkatch T, Perez-Garci E, Gallaraga E, Bargas J, Hamm H, Surmeier DJ (2000): D2 dopamine receptors in striatal medium spiny neurons reduce Ltype $\mathrm{Ca}^{2+}$ currents and excitability via a novel PLC $\beta 1$ $\mathrm{IP}_{3}$-calcineurin-signaling cascade. J Neurosci 20:89878995

Hsu KS, Huang CC, Yang CH, Gean PW (1995): Presynaptic D2 dopaminergic receptors mediate inhibition of excitatory synaptic transmission in rat neostriatum. Brain Res 690:264-268

Ito R, Dalley JW, Howes SR, Robbins TW, Everitt BJ (2000): Dissociation in conditioned dopamine release in the nucleus accumbens core and shell in response to cocaine cues and during cocaine-seeking behavior in rats. J Neurosci 20:7489-7495

Jaeger D, Kita H, Wilson CJ (1994): Surround inhibition among projection neurons is weak or nonexistent in the rat neostriatum. J Neurophysiol 72:2555-2558

Jiang Z-C, North RA (1991): Membrane properties and synaptic responses of rat striatal neurones in vitro. J Physiol 443:533-553

Johanson C-E, Schuster CR (1995): Cocaine. In Bloom FE, Kupfer DJ (eds), Psychopharmacology: The Fourth Gof Progress. New York, Raven Press, pp 1685-1697

Kaneko S, Hikida T, Watanabe D, Ichinose H, Nagatsu T, Kreitman RJ, Pastan I, Nakanishi S (2000): Synaptic integration mediated by striatal cholinergic interneurons in basal ganglia function. Science 289:633-637

Kelly PH, Seviour PW, Iversen SD (1975): Amphetamine and apomorphine responses in the rat following 6-OHDA lesions of the nucleus accumbens septi and corpus striatum. Brain Res 94:507-522

Kincaid A, Wilson CJ (1996): Corticostriatal innervation of the patch and matrix in the striatum. J Comp Neurol 374:578-592

Kita H (1996): Glutamatergic and GABAergic postsynaptic responses of striatal spiny neurons to intrastriatal and cortical stimulation recorded in slice preparations. Neuroscience 70:925-940

Kita T, Kita H, Kitai ST (1984): Passive electrical membrane properties of rat neostriatal neurons in an in vitro slice preparation. Brain Res 300:129-139

Kiyatkin EA, Rebec GV (2000): Dopamine-independent action of cocaine on striatal and accumbal neurons. Eur J Neurosci 12:1789-1800

Knowlton BJ, Mangels JA, Squire LR (1996): A neostriatal habit learning system in humans. Science 273:1399-1402

Koob GF, Sanna PP, Bloom FE (1998): Neuroscience of addiction. Neuron 21:467-476

Koos T, Tepper JM (1999): Inhibitory control of neostriatal projection neurons by GABAergic interneurons. Nat Neurosci 2:467-472

Kuczenski R, Segal DS, Aizenstein ML (1991): Amphetamine, cocaine, and fencamfamine: relationship between locomotor and stereotypy response profiles and caudate and caudate and accumbens dopamine dynamics. J Neurosci 11:2703-2712

LaHoste GJ, Henry BL, Marshall JF (2000): Dopamine D1 receptors synergize with D2, but not D3 or D4, receptors in the striatum without the involvement of action potentials. J Neurosci 20:6666-6671

Lenz S, Perney TM, Qin Y, Robbins E, Chesselet MF (1994): GABA-ergic interneurons of the striatum express the Shaw-like potassium channel Kv3.1. Synapse 18:55-66

Levine MS, Li Z, Cepeda C, Cromwell HC, Altemus KL (1996): Neuromodulatory actions of dopamine on synaptically-evoked neostriatal responses in slices. Synapse 24:65-78

Lin YJ, Greif GJ, Freedman JE (1996): Permeation and block of dopamine-modulated potassium channels on rat striatal neurons by cesium and barium. J Neurophysiol 76:1413-1322

Lyons D, Friedman DP, Nader MA, Porrino LJ (1996): Cocaine alters cerebral metabolism within the ventral striatum and limbic cortex of monkeys. J Neurosci $16: 1230-1238$

Mansour A, Watson SJ (1995): Dopamine receptor expression in the central nervous system. In Bloom FE, Kupfer DJ (eds), Psychopharmacology: The Fourth Generation of Progress. New York, Raven Press, pp 207-219

McGeorge AJ, Faull RLM (1989): The organization of the projection from the cerebral cortex to the striatum in the rat. Neuroscience 29:503-537

Moratalla R, Vickers EA, Robertson HA, Cochran BH, Graybiel AM (1993): Coordinate expression of c-fos and junB is induced in the rat striatum by cocaine. J Neurosci 13:423-433

Nicola SM, Malenka RC (1998): Modulation of synaptic transmission by dopamine and norepinephrine in ventral but not dorsal striatum. J Neurophysiol 79:17681776

Nisenbaum ES, Berger TW (1992): Functionally distinct subpopulations of striatal neurons are differentially regulated by GABAergic and dopaminergic inputs. I. In vivo analysis. Neuroscience 48:561-578

Parthasarathy HB, Graybiel AM (1997): Cortically driven immediate-early gene expression reflects modular influence of sensorimotor cortex on identified striatal neurons in the squirrel monkey. J Neurosci 17:2477-2491

Paxinos G, Watson C (1986): The Rat Brain in Stereotaxic Coordinates. Sydney, Academic Press

Penney JB, Young AB (1983): Speculation on the functional anatomy of basal ganglia disorders. Annu Rev Neurosci 6:73-94

Pisani A, Bonsi P, Centonze D, Calabresi P, Bernardi G (2000): Activation of D2-like dopamine receptors reduces synaptic inputs to striatal cholinergic interneurons. J Neurosci 20:RC69

Plenz D, Kitai ST (1998): Up and down states in striatal medium spiny neurons simultaneously recorded with spontaneous activity in fast-spiking interneurons studied in cortex-striatum-substantia nigra organotypic cultures. J Neurosci 18:266-283

Qiao JT, Dougherty PM, Wiggins RC, Dufny N (1990): Effects of microiontophoretic application of cocaine, alone and with receptor antagonists, upon the neurons of the medial prefrontal cortex, nucleus accumbens and caudate nucleus of rats. Neuropharmacology 29:379-385 
Saint-Cyr JA, Taylor AE, Lang AE (1988): Procedural learning and neostriatal dysfunction in man. Brain 111:941959

Schiffmann SN, Lledo P-M, Vincent J-D (1995): Dopamine D1 receptor modulates the voltage-gated sodium current in rat striatal neurones through a protein kinase $\mathrm{A}$. J Physiol 483:95-107

Seiden LS, Sabol KE, Ricaurte GA (1993): Amphetamine: effects on catecholamine systems. Annu Rev Pharmacol Toxicol 32:639-677

Stein EA, Fuller SA (1993): Cocaine's time action profile on regional cerebral blood flow in the rat. Brain Res 626: $117-126$

Stern EA, Jaeger D, Wilson CJ (1998): Membrane potential synchrony of simultaneously recorded striatal spiny neurons in vivo. Nature 394:475-478

Surmeier DJ, Bargas J, Hemmings HG, Nairn AC, Greengard P (1995): Modulation of calcium currents by a D1 dopaminergic protein kinase/phosphatase cascade in rat neostriatal neurons. Neuron 14:385-397

Surmeier DJ, Song W-J, Yan Z (1996): Coordinated expression of dopamine receptors in neostriatal medium spiny neurons. J Neurosci 16:6579-6591

Whishaw IQ, Mittleman G, Bunch ST, Dunnett SB (1987): Impairments in the acquisition, retention and selection of spatial navigation strategies after medial caudateputamen lesions in rats. Behav Brain Res 24:125-138

White FJ, Hu XT, Henry DJ (1993): Electrophysiological effects of cocaine in the rat nucleus accumbens: microiontophoretic studies. J Pharmacol Exp Ther 266:10751084

Wickens JR, Kotter R, Alexander ME (1995): Effects of local connectivity on striatal function: stimulation and analysis of a model. Synapse 20:281-298

Wilson CJ, Groves PM (1980): Fine structure and synaptic connections of the common spiny neuron of the rat neostriatum: a study employing intracellular injection of horseradish peroxidase. J Comp Neurol 194:599-615

Wilson CJ, Kawaguchi Y (1996): The origins of two-state spontaneous membrane potential fluctuations of neostriatal spiny neurons. J Neurosci 16:2397-2410

Yamamoto BK, Spanos JL (1988): The acute effects of methylenedioxymethamphetamine on dopamine release in the awake-behaving rat. Eur J Pharmacol 148:195-203

Yung KK, Smith AD, Levey AI, Bolam JP (1996): Synaptic connections between spiny neurons of the direct and indirect pathways in the neostriatum of the rat: evidence from dopamine receptor and neuropeptide immunostaining. Eur J Neurosci 8:861-869 